\title{
Cultura política massmediática. El origen de la grieta
}

\section{Mass media political culture. The origin of the crack}

\author{
Liliana Demirdjian lilidemir@yahoo.com.ar \\ https://orcid.org/0000-0003-3686-5973
}

Universidad Nacional de Buenos Aires/ Universidad Nacional de Tres de Febrero, Argentina

\section{Resumen}

Las transformaciones recientes ocurridas en el campo comunicacional han impactado en todos los órdenes de la vida social. Este artículo se centrará en aquellas relativas al orden político. Se revisarán, los distintos modos utilizados para describir las diversas formas en que ha devenido la democracia, todas las cuales, compartiendo un espíritu similar, intentan interpretar el escenario que se configura con el advenimiento de los medios como actores centrales de la vida política. Se trata de caracterizaciones tales como democracia de audiencias, democracia de opinión, democracia mediática o mediocracia. Es decir, formas de democracia en la que los medios, efectivamente, ejercen el poder y en virtud del cual se establecen las condiciones en las que se producen la deliberación y la formación de la opinión en la actualidad. Este breve 
recorrido de carácter conceptual servirá como encuadre para aproximar algunos rasgos distintivos de la denominada cultura política massmediática. En esta línea se realizará una primera aproximación al caso argentino para observar el modo en qué los medios enmarcaron la vida política y, en función de un tipo de discursividad específica, establecieron ciertos parámetros de sentido sobre la realidad sociopolítica en el contexto de un año electoral.

Palabras Clave: democracia; comunicación; cultura; política.

\section{Abstract}

The recent transformations that the comunication field has experimented, have impacted in all the orders of the social life. This article will particulary focus on the emergency of differents denominations for democracy, which share a similar spirit and try to interpret the scenario that the advent of the media as the main actor of the politic life has configured. These definitions include terms as audience's democracy, opinion's democracy, media's democracy or mediocracy. In other words, forms of democacy in which the media exercises the power effectivily and sets up the conditions in which deliberation and public opinion are produced nowadays. This brieft conceptual journey will be useful as a frame to approach to some distinctive traits of the massmediatic politic culture. Along these lines, it is intended to create a first approximation to the way in which the media framed political life with their specific kind of discourse to define some sense's parameters about sociopolitical reality in this electoral year's context.

Keywords: democracy; communication; culture; politics.

\section{Introducción}

Si nos remontamos en el tiempo, democracia fue el nombre que se le dio al régimen político nacido en el siglo de Pericles. El mismo tuvo su origen en los términos griegos demos: pueblo y kratos: poder. Esta forma de gobierno, en la que el poder se encontraba en manos del pueblo, se sustentaba en dos principios que aquí nos interesarán especialmente, el principio de isonomía y el de isegoría. 
El principio de isonomía implicaba igualdad ante la ley para aquellos que eran considerados ciudadanos. Por su parte, el principio de isegoría suponía la igualdad de todos los ciudadanos a manifestar sus ideas y a ser escuchados. En este sentido, es posible comprender que el principio de isegoría hacía alusión, en aquel mundo de la polis, a eso que muchos siglos más tarde los modernos denominaron libertad de expresión. Cualquier ciudadano tenía derecho a que su palabra llegara al resto de sus pares, a opinar en público y a participar en las discusiones que se producían en la ecclesía o asamblea. De ahí la importancia de adquirir capacidades retóricas. En ese contexto la ciudadanía suponía participación efectiva, es decir, no solo el derecho a votar. Antes bien, a tener voz propia en las discusiones relacionadas con los asuntos de interés común que se debían debatir y que recién luego podían ser sometidos a elección. Así, la figura de Pericles, el gran orador, se convierte para nosotros, en el seno de democracias indirectas y definitivamente mediatizadas, en una referencia obligada para pensar la ciudadanía en términos de las posibilidades de ejercer el uso de la palabra en el espacio público mediático. En aquel momento fundacional de la democracia resultaba claro que la utilización de los recursos persuasivos de la retórica contribuía al triunfo electoral de aquellos que mejor los aplicaran. Eventualmente, se contaba con la anuencia de la mayoría del electorado, en función de las destrezas argumentativas puestas en acto por cada uno de los que asistían a la asamblea para defender alguna posición sobre los temas que formaban parte de las preocupaciones del conjunto. De ahí la relevancia que tenían los sofistas. Y también la profunda contradicción que Sócrates guardaba con estos personajes que, según consideraba, gracias a su capacidad argumentativa, podían tener éxito sin garantizar la más mínima justicia para la ciudad. Un ejemplo, al respecto, se observa en el desacuerdo que sostiene con la visión sobre la justicia que defiende Trasímaco en la República. ${ }^{1}$

En las sociedades contemporáneas la mediatización le otorgó un nuevo estatuto al espacio público (Wolton, Ferry, 1998). Esto implicó una transformación en los modos de la argumentación y de la deliberación que ahora serán encarnadas por nuevos protagonistas. Por ello, en paralelo con el proceso de mediatización se han ido reconfigurando las formas de la representación y la participación política. Es preciso considerar, entonces, la relevancia que

\footnotetext{
${ }^{1}$ En este diálogo Sócrates se opone enfáticamente a la visión de Trasímaco, quien afirma que justo es lo que resulta conveniente al más fuerte. Para Sócrates justo no es aquello que le conviene a quien se encuentra en el poder. Ejercer el gobierno en beneficio propio resulta injusto, ya que el arte de gobernar se debe ejercer siempre en beneficio de los gobernados (Platón, 1988: 338 c).
} 
asumen los actores involucrados en este nuevo espacio público, sobre cuya agencia se estructura gran parte de la vida social en la actualidad.

La dinámica que establece la comunicación mediatizada conduce, a su vez, a una cultura política de nuevo tipo signada por un régimen que funciona bajo la lógica de una aparente absoluta visibilidad.

Ello no lo exime, sin embargo, de la presencia de opacidades. Todos estos hechos perfilan, pues, el marco en el que tienen lugar hoy los procesos sociopolíticos y le imponen nuevos rasgos a nuestras democracias.

Este conjunto de cuestiones, que constituyen parte del núcleo vital de la política, nos guiarán en el abordaje de la relación entre democracia y comunicación en el mundo contemporáneo. En las páginas que siguen nos interesará revisar las formas en que en años recientes se hizo referencia a la democracia en función de la creciente centralidad que asumió la dimensión comunicativa.

Emprendemos este recorrido entendiendo que los modos del decir marcan, en un determinado tiempo y espacio, los fenómenos que elegimos abordar.

¿De la democracia a la mediocracia?

Las modificaciones ocurridas en el plano comunicacional en el transcurso de la segunda mitad del pasado siglo impactaron sobre el orden político y, por ende, interpelaron los modos de nombrar a la democracia, dando lugar a la aparición de nuevas y diversas formas de denominarla. Todas ellas, compartiendo un espíritu similar, intentaron expresar la creciente influencia que la evolución de los medios masivos tenía sobre el régimen político. En la búsqueda, entonces, por encontrar términos que permitiesen interpretar esta situación se llegó a caracterizaciones tales como democracia de audiencias (Manin, Bernard 1993), democracia de opinión (Sartori, Giovanni, 1998) o mediocracia (Castells, Manuel, 1995; Champagne, Patrick, 1998; Monedero, Juan Carlos, 2010; Quiroga, Hugo, 1996; Trejo Dalarbe, Raúl, 2001). Al conceptualizar la democracia de audiencias, el francés Bernard Manin intenta dar cuenta de la metamorfosis que atravesó la representación política como resultado del advenimiento de los medios audiovisuales. Por su parte, al proponer la noción democracia de opinión, el politólogo italiano Giovanni Sartori, aclara que la opinión pública en la actualidad es la opinión formada por la acción de los medios de comunicación y, por ello mismo, precisa que la idea de la democracia como un gobierno de opinión es en un todo coherente y "se adapta perfectamente a la aparición de la vídeo-política" (Sartori, 1998, p. 66). Asimismo, los autores que proponen 
utilizar el término mediocracia intentan aludir a la definitiva centralidad que tienen los medios en la vida democrática.

Esta serie de nuevas denominaciones resultaron del intento de ajustar la noción teórica de democracia a la realidad política derivada de la evolución de las tecnologías de la comunicación y a la definitiva hegemonía audiovisual que se produjo en las sociedades contemporáneas (Verón Eliseo, 2001; 2009). Con este fin, también se propuso la noción de democracia mediática, en cuyo seno se han suscitado dos visiones divergentes sobre el papel que juegan los medios en la comunicación política (Exeni José Luis, 2000. p. 5). Por una parte, la visión mediófila se enfoca en una democracia centrada en los medios y en las contribuciones que éstos pueden aportar en un sistema representativo. Esta perspectiva pone especial atención en la importancia que tiene la comunicación mediatizada y su capacidad de fijar agenda política. Por el contrario, la visión mediófoba plantea un corrimiento que pasa de valorar positivamente el aporte que los medios pueden realizar a la democracia representativa a establecer una valoración de signo negativo sobre la mediatización.

Esta visión pone el énfasis en los condicionamientos que los medios le imponen a la democracia, hasta el punto en el que éstos pasan a formar parte del gobierno. En continuidad con esta visión y retomando la concepción sobre la democracia como poliarquía propuesta por Robert Dahl (1999), es posible afirmar que asistimos al pasaje de una poliarquía a una mediarquía. Esta denominación refuerza la posición que sugiere que en las democracias actuales son los medios quienes, efectivamente, ejercen el poder. En virtud de las condiciones en las que se producen la deliberación y la formación de la opinión en este nuevo contexto, la visión mediófoba supone que la opinión pública queda sumergida en el océano de los sondeos $y$, por esto mismo, sujeta a la probabilidad de ser manipulada. En lugar de ello, entre las bondades de esta nueva etapa signada por el desarrollo de los medios, la visión mediófila destaca la emergencia de una democracia del público o de audiencias, que como ya se mencionó ha caracterizado detalladamente Bernand Manin (Exeni, 2000, p. 24; Manin, 1995). En este marco general que hemos intentado aproximar asumimos que, aún en la sociedad red, los tradicionales medios masivos - por cierto, en permanente ejercicio de aggiornamiento de sus rutinas y formatos a la dinámica propia de las redes sociales- continúan teniendo un papel trascendente en la formación de opinión. Nos proponemos, pues, en el siguiente apartado, una primera interpretación sobre el modo en que los medios audiovisuales de mayor relevancia nacional enmarcaron (Sádaba, 2007) la vida política en el contexto de años electorales recientes. 
Cultura política massmediática: el devenir de una "grieta"

Uno de los rasgos más fuertes que atraviesa la cultura política local en los últimos años se expresa en la polarización extrema de las preferencias políticas de la ciudadanía. ${ }^{2}$ Dicha polarización se puede resumir en la dicotomía kirchnerismo/antikirchnerismo y reedita la que surgiera a partir de 1945 entre sectores peronistas y antiperonistas (Grimson, 2019). En vistas a observar de qué manera la noción de cultura política massmediática propuesta por Luis Alberto Quevedo (1997), permanece vigente y continúa ofreciendo elementos interesantes para el análisis de la coyuntura actual ${ }^{3}$, nos abocaremos al análisis de la televisión abierta. Tomaremos el caso particular de Canal 13, propiedad del Grupo Multimedios Clarín y nos centraremos en dos figuras relevantes de su programación: el periodista Jorge Lanata, quien conduce los domingos por la noche el programa Periodismo Para Todos (PPT) y la conductora Mirtha Legrand, quien encabeza los sábados por la noche el programa La noche de Mirtha y los domingos al mediodía Almorzando con Mirtha Legrand.

Es evidente que entre ambas figuras aparece casi enteramente cubierta la programación del canal en los horarios centrales del fin de semana. Este hecho no resulta un dato menor ya que la fijación de agenda que éste propone de lunes a viernes, con la emisión de los noticieros diarios, queda virtualmente en suspenso durante los sábados y domingos.

La discursividad mediática del primer semestre de 2019 -año de elecciones nacionales - estuvo signada por una temática recurrente que hizo centro en la idea de que existe una grieta que

2 En la emisión del 11 de diciembre de 2019 del programa Nada Personal, emitido por Canal 9 de Buenos Aires, el saliente presidente de la Cámara de Diputados, Emilio Monzó, declara que siempre mantuvo una posición contraria a la estrategia electoral de polarización de su espacio político (Cambiemos). Y resume que, si bien razones sociológicas más profundas que permitan explicar el origen de la grieta pueden remontarse a un momento anterior, en la historia política reciente, fue el denominado conflicto del campo derivado de la puja de intereses desatada en 2008 a raíz de la Resolución 125 destinada a aplicar retenciones al sector agropecuario, la que marca un punto de inflexión y el retorno de la radical fractura de la sociedad argentina.

3 Ello no obsta que la noción de cultura política massmediática, en algunas dimensiones, requiera cierta resignificación, complejización y ajuste a la nueva realidad surgida de las transformaciones ocurridas en el orden comunicacional. 
divide a la sociedad argentina, tal como se puede observar en la tapa de la revista Noticias en su número de abril de ese año.

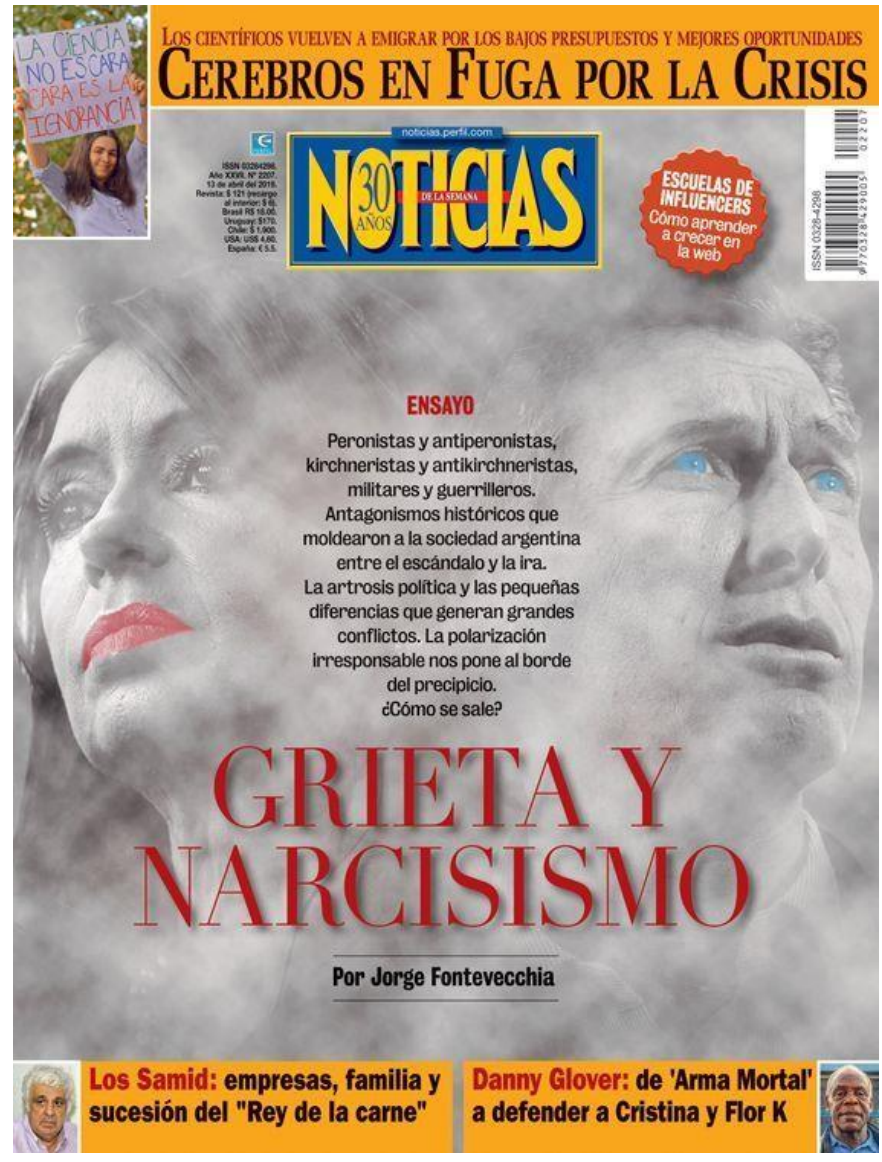

Figura 1. 13 de abril del 2019. Tapa de Revista Noticias. (Fuente: recuperado de: https://noticias.perfil.com/noticias/tapas/2019-04-12-argentina-grieta-ynarcisismo.phtml\#lg=1\&slide=0)

Esta cuestión no fue un tópico para referir exclusivamente a la política de orden nacional, sino que se trasladó también al ámbito provincial con la misma efectividad. La siguiente imagen da cuenta que los medios reforzaron y potenciaron la relevancia de este tópico y, por tanto, que las distintas plataformas políticas recurrieron a la temática de modo constante como parte de sus propuestas. 


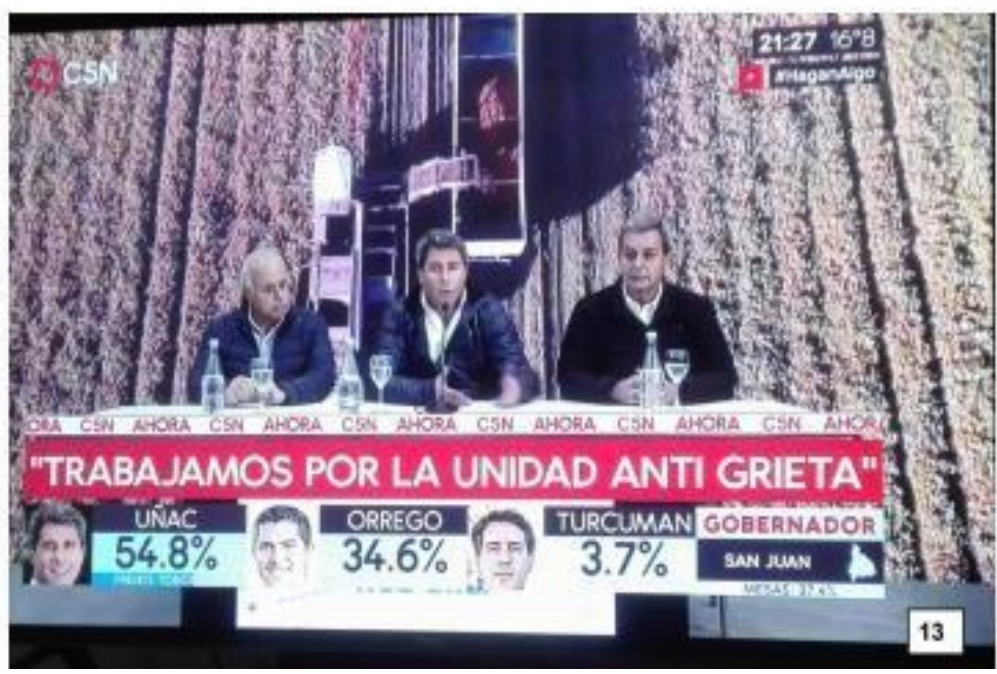

Figura 2. (Fuente: elaboración propia)

La grieta resulta así una construcción de sentido fundamentalmente creada por los medios de comunicación (González Horacio, 2010; 2013; 2018). A partir del año 2015 dicha construcción tuvo un creciente uso a instancias de la labor de algunos protagonistas del universo mediático y, específicamente, del audiovisual, a quienes, según recuerda Horacio González, Oscar Landi caracterizó como «intelectuales de la televisión» (González, 2018).

Si bien los programas encabezados por las dos figuras aquí mencionadas forman parte de géneros distintos, responden a una lógica que resulta cada vez más habitual en la televisión argentina: la yuxtaposición o hibridación de géneros. Lanata hace periodismo político. Su estilo conjuga la investigación periodística y el análisis político con el humor. En este sentido, su programa Periodismo Para Todos intenta escapar al canon tradicional de los programas políticos e incluye el uso del humor.

Un tipo de humor que apela a cierta dosis de ironía, parodia y sátira. Sobre este punto se destaca el espacio central que ocupa dentro del programa el sketch de humor político, una especie de parodia satírica que se repite, bajo diferentes títulos, año tras año. En la temporada 2017 el mismo se tituló The house of Grieta, al año siguiente Verano del 18 y luego, en la temporada 2019, Argentina. Tierra de rencor y venganza. En rigor, estos sketchs han sido promocionados por el Canal como sitcoms y se han disponibilizado por capítulos de manera independiente al programa Periodismo Para Todos. ${ }^{4}$ Nótese que, entonces, se ha naturalizado

\footnotetext{
${ }^{4}$ Los capítulos de las así caracterizadas comedias de situación se encuentran disponibles en la página web de Canal 13. A modo de ejemplo un capítulo correspondiente a la temporada 2019 se puede Question, Vol. 1, N. ${ }^{\circ}$ 65, abril 2020. ISSN 1669-6581

Instituto de Investigaciones en Comunicación | Facultad de Periodismo y Comunicación Social | Universidad Nacional de La Plata La Plata | Buenos Aires | Argentina 
la presencia de una comedia de situación en el seno de un programa de periodismo político. Por su parte, si bien los programas que conduce Mirtha Legrand son catalogados como de interés general ${ }^{5}$, ellos resultan, eminentemente, programas atravesados por la política. No solo porque asiduamente cuenta con invitados que forman parte de la clase política y de periodistas especializados en la materia, sino también porque las cuestiones políticas constituyen un tema recurrente en sus mesas. Por estas razones, se trata de dos casos de estudio de interés para abordar esa dimensión que Quevedo refería como cultura política massmediática. El primero, luego seguido por muchos, en utilizar la palabra grieta fue el periodista Jorge Lanata en una contratapa del periódico Página $/ 12^{6}$ a fines de los años ochenta cuando era su director. Lanata, realizó un giro en su trayectoria profesional. Este giro le permitió transitar no solo de la gráfica al mundo audiovisual, sino también desde un espacio del mapa político a otro radicalmente distinto.

Sus seguidores: lectores, radioescuchas y televidentes, comenzaron a cambiar. Sus productos empezaron a ser consumidos por sectores políticos muy diferentes de aquellos que lo habían sabido seguir en sus inicios. Su programa Periodismo Para Todos marcó la línea del periodismo de oposición al gobierno de Cristina Fernández de Kirchner. ${ }^{7}$ Dentro de esa línea, encabezó la cruzada contra colegas con los cuales había compartido espacios de trabajo en otras épocas de su vida dentro del oficio periodístico. Dado que adscribían al kirchnerismo ${ }^{8}$, los acusó de no hacer periodismo, sino de hacer propaganda. De este modo, negaba que todo lugar de enunciación remite a una inscripción ideológica e intentaba reforzar el supuesto de la «objetividad periodística», lugar que se auto adjudicó.

La grieta, o fractura entre dos sectores radicalmente opuestos, ha sido un factor recurrente en el desarrollo histórico nacional, que se ha cristalizado en múltiples relaciones políticas dicotómicas.

visualizar en el siguiente enlace: https://www.eltrecetv.com.ar/videos/periodismo-para-todos2019/argentina-tierra-de-rencory-venganza-mauricio-escapo-del-tribunal_116285

5 De acuerdo con el criterio de la Asociación de Periodistas de Radio y Televisión Argentina (APTRA), por ejemplo.

${ }^{6}$ En efecto, la contratapa del periódico Página /12 del domingo 16 de abril de 1989 firmada por Jorge Lanata se tituló La Grieta. En 1987 Lanata había fundado este periódico que se destacó por sus tapas y por tener una amplia circulación en sectores políticos pertenecientes al espacio progresista.

${ }^{7}$ El nombre del programa Periodismo Para Todos apuntaba a interpelar al gobierno de Cristina Fernández de Kirchner que en 2009 terminó con la privatización de la televisación del fútbol y puso al aire en la TV Pública el programa Futbol Para Todos que televisaría nuevamente los partidos de la Primera División y de las semifinales y finales de la Copa Libertadores y de la Copa Sudamericana en las cuales participaran equipos nacionales.

\footnotetext{
${ }^{8}$ Ver: La Nación, 13/10/2011 y Rosario Nuestro, 15/11/2017.

Question, Vol. 1, N. ${ }^{\circ}$ 65, abril 2020. ISSN 1669-6581
}

Instituto de Investigaciones en Comunicación | Facultad de Periodismo y Comunicación Social | Universidad Nacional de La Plata 
Desde la puja entre la tradición liberal y la nacional-popular, fue adquiriendo diversos nombres: unitarios y federales, peronistas y gorilas, yrigoyenistas y antipersonalistas, entre otros. «No hay un hilo invisible de la Revolución de Mayo a Intratables ${ }^{9}$, pero sí un choque recurrente de proyectos y una ostensible dificultad para sostener colectivamente los cambios" (Natanson José, 2019). Sin embargo, fue Jorge Lanata -ahora periodista del Grupo Multimedio Clarínquién, desde la televisión, pero también desde su programa en AM Radio Mitre, recuperó el término grieta que, según anticipamos, ya había utilizado a finales de los años ochenta para señalar la división entre quienes añoraban a los militares y quienes los veían con espanto. En aquella etapa, marcada por la complejidad que supuso la transición a la democracia, el término grieta era utilizado para describir una sociedad que se dividía entre aquellos que ponían un límite claro al declarar que nunca más se podían volver a repetir los hechos sucedidos durante la dictadura cívico-militar iniciada en 1976 y quienes aún la justificaban. En cambio, en este nuevo momento histórico, Lanata utiliza el término grieta para describir una sociedad dividida entre quienes apoyan al kirchnerismo y quienes se asumen definitivamente antikirchneristas.

Si bien una parte importante del periodismo interpretó que la decisión de Cristina Fernández de Kirchner de elegir a Alberto Fernández para que encabezara la fórmula presidencial por el Frente de Todos constituía una señal que apelaba a cerrar la grieta ${ }^{10}$, Lanata no adhirió a esta lectura.

En 2019, el sketch de humor político del programa Periodismo Para Todos se tituló Argentina. Tierra de rencor y venganza en alusión al título de una novela emitida semanalmente por el mismo canal. ${ }^{11}$ En esta temporada se plantea la situación del país en caso de que triunfe el kirchenrismo en las elecciones nacionales de octubre y aparece en cada emisión el personaje de Cristina Fernández de Kirchner ejerciendo justicia de manera absolutamente arbitraria, una mujer desmedida que acusa y juzga a voluntad, que manipula, hace y deshace según su humor. La figura de Alberto Fernández, su compañero de fórmula y entonces candidato a

9 Intratables es un programa argentino que se transmite por el Canal América de formato tipo magazine en el que un grupo de panelistas discute diversos temas de actualidad junto con los diversos invitados que transitan el estudio.

${ }^{10}$ Al conocerse la fórmula presidencial propuesta por la ex presidenta, Carlos Verna publicaba el 19 de mayo en Clarín una nota titulada: «Cristina busca cerrar la grieta». Así también, luego del triunfo de la fórmula Fernández-Fernández en las elecciones Primarias Abiertas Simultáneas y Obligatorias (PASO) y un mes antes de las elecciones nacionales, la Revista de humor político Barcelona, en su tapa del 27 de septiembre de 2019, titula Grieta is over junto con una caricatura de los protagonistas de la fórmula desnudos y mirando hacia atrás, en clara alusión a las figuras de John Lennon y Yoko Ono, en su etapa de abierto compromiso pacifista.

${ }^{11}$ Argentina. Tierra de amor y venganza.

Question, Vol. 1, N. ${ }^{\circ}$ 65, abril 2020. ISSN 1669-6581

Instituto de Investigaciones en Comunicación | Facultad de Periodismo y Comunicación Social | Universidad Nacional de La Plata La Plata | Buenos Aires | Argentina

Página 10 de 18 
presidente de la nación, aparece como un títere que ella maneja junto a su hijo Máximo Kirchner. En relación con el uso del humor y la parodia, cabe mencionar la popularidad adquirida por la imitadora Fátima Florez, quien con su papel de Cristina Fernández formó parte protagónica del sketch humorístico de varias temporadas de Periodismo Para Todos. Como toda nueva figura en ascenso, también participó en más de una ocasión de los programas de Mirtha Legrand. La última vez que fue invitada a compartir su mesa fue en la noche del 30 de junio de 2019. En dicha emisión insertó parodias de Cristina Fernández de Kirchner mientras dialogaba con la dirigente anti kirchnerista Lilita Carrió, quien también se encontraba entre las invitadas a cenar en esa misma mesa. De este modo, la frontera entre lo ficcional humorístico y lo real aparecían difusas y conducían al equívoco permanente: sutil dispositivo que contribuye a la manipulación de la televidencia.

Mirtha Legrand, que en su juventud fue protagonista de la época de oro del cine argentino, para devenir luego en conductora televisiva, se cuenta dentro de las referencias obligadas de nuestra cultura política massmediática y fue una de las célebres cultoras de la grieta. En su pasaje de la pantalla cinematográfica a la televisiva, la ex actriz se convirtió en una líder de opinión. Su programa constituye un clásico de la televisión argentina que, al ser considerado dentro del rubro interés general, puede funcionar en los bordes, en un espacio que permite entrar y salir de los temas y problemas de la política con la rapidez que impone el vivo televisivo. Mirtha Legrand, quien suele almorzar y cenar con figuras de la clase política y del periodismo, compartió su mesa en más de una ocasión con el periodista Jorge Lanata. Al respecto, un dato de interés lo constituye la cena que mantuvieron a solas en la noche del sábado anterior a la jornada electoral de medio término del año 2017. En ese programa ambos jugaron a no romper la veda electoral al tiempo que no dejaron de hacer proselitismo sobre todos y cada uno de los temas sensibles que podían resultar de influencia para la decisión que el electorado, en ese momento mera audiencia, debía tomar al día siguiente en el cuarto oscuro. La cena a solas con el periodista fue, de comienzo a fin, un programa veladamente político.

La conductora fue y, por cierto, continúa siendo una de las figuras televisivas más relevantes dentro de la oposición mediática al kirchnerismo. Oposición cuya intensidad se agudizó a medida que se acercaba la elección presidencial de 2015 y que cobra un nuevo énfasis en el contexto electoral del 2019. En rigor, La Chiqui o la Legrand, como suelen mencionarla en los mismos medios, sumó toda su experiencia televisiva a la candidatura presidencial de Cambiemos en 2015. De hecho, no dudó en mirar a cámara y llamar a votar por Mauricio Macri. Una vez consagrado presidente de la nación, le cursó una invitación a la conductora para visitar la casa de gobierno. Y luego la recibió ofreciéndole, precisamente, un almuerzo en mayo 
de 2016, cuando ella se mostró crítica en relación con algunas medidas tomadas en los primeros tramos de su gestión (Sarlo, 2019). ${ }^{12}$

Esta posición no impidió que en febrero de 2018 el presidente estuviera, junto con otros nombres centrales de la dirigencia política de Cambiemos, entre sus invitados al festejo que realizó al cumplir 91 años. En un artículo presentado al Seminario "Comunicación y Política: ¿hay un lugar para la política en la cultura mediática?» organizado en la Universidad Nacional de Córdoba a inicios de noviembre de 1991, Silvia Tabachnik se refirió, a propósito de la televisación de los almuerzos de Mirtha Legrand, a una serie de aspectos que podríamos considerar constitutivos de su éxito no solo televisivo sino también, y más importante aún, como promotora y pieza central del entramado de esa particular arista de la cultura política que Quevedo denominaba massmediática. En aquel trabajo, que fuera publicado un año más tarde con el título La Anfitriona, Tabachnik se preguntaba “¿De qué "materia” está hecha esta maestra de ceremonias, esta pedagoga de las buenas formas, que cada mediodía pone en pantalla su mejor perfil, para comandar el almuerzo arquetípico de los notables?». La pregunta que se formulaba la autora del artículo al que aquí estamos refiriendo continúa siendo, un cuarto de siglo más tarde, de gran pertinencia y actualidad si observamos que la Anfitriona además de mantenerse en el aire, tiene la capacidad de influir políticamente en amplios sectores de la población. Y lo más interesante quizá sea que puede hacerlo con la misma fórmula inaugurada décadas antes del cambio tecnológico. Antes, incluso, del pasaje de la paleo a la neo televisión que identificara Umberto Eco y sobre el que Eliseo Verón se detuviera a reflexionar (Verón, 2009). Se trata de un programa cuyo formato es propio de la paleo televisión, a pesar de lo cual, pervive en el contexto de la neo televisión. Por ello mismo la figura de la Anfitriona resulta un caso paradigmático a la hora de abordar el estudio de la cultura política desde su dimensión massmediática. En un mundo en el que todo se modifica aceleradamente, y en el que el ingreso en la sociedad red condujo a los productos mediáticos a

12 «Mirtha Legrand no hizo campaña por Alfonsín, como más de treinta años después haría por Macri, de quien hoy no la separa sino la coyuntura en la que ella representa al votante macrista impaciente o desilusionado. Por el contrario, de Alfonsín la separaba un mundo de valores e ideas. Mirtha Legrand es sólidamente conservadora, aunque sus preguntas puedan, algunas pocas veces, indicar que se ha ido sensibilizando» (Sarlo, 2019). En efecto, su ideología conservadora resulta explícita. Por citar solo dos referencias haremos mención de la pregunta formulada, en el contexto del debate por el matrimonio igualitario, en su programa del 12/7/2010. En ese almuerzo le preguntó al diseñador de modas Roberto Piazza sobre el riesgo de que padres adoptivos homosexuales violaran a sus hijos. La segunda cita obligada refiere a la pregunta formulada a la cantante Laura Miller en 2015, en el contexto de las movilizaciones masivas contra la violencia de género, la diva le preguntó a la cantante: ¿Pero vos qué hacías para que te pegara? ¿Hiciste algo anormal, algo raro?

Question, Vol. 1, N. ${ }^{\circ} 65$, abril 2020. ISSN 1669-6581

Instituto de Investigaciones en Comunicación | Facultad de Periodismo y Comunicación Social | Universidad Nacional de La Plata La Plata | Buenos Aires | Argentina

Página 12 de 18 
un vertiginoso proceso de transformación, su fórmula televisiva se mantiene intacta. Las modificaciones resultan apenas cuestión de estilo: de los buquets de rosas rococó rosadas a cómo te ven, te tratan..., constituyen recursos que forman parte de la construcción de un personaje cuyo rol pedagógico va del buen gusto para servir la mesa al lema de autoayuda que sirve de sostén para las y los partícipes de su gala gastronómica, en ese privilegiado lugar de encuentro que provee el espacio público mediático. Se trata de una sumatoria de elementos que aparentan tener un origen espontáneo pero que se encuentran meticulosamente estudiados y son los que le han garantizado un sostenido rating a lo largo de las décadas. Ya no solo oficia como maestra de ceremonias de elegantes almuerzos, además suma a los mismos la invitación a la ceremonia de cenar los sábados por la noche, típico día de salidas sociales y no de doméstica cena frente al televisor. En esta etapa, a la que Renato Ortiz refiere como modernidad mundo (Ortiz, 1997; 2005) y en la que, según afirma el antropólogo brasilero, las identidades se forjan fundamentalmente en relación con referentes propios del mundo del consumo y con un fuerte estímulo de la idea de juventud, la Anfitriona que supera ya los noventa años rompe todos los pronósticos. Ella se jacta de sobrevivir a los cambios tecnológicos y a la salvaje lucha por el rating. Un claro ejemplo de la batalla constante que libra la nonagenaria diva por mantener su vigencia y saciar su sed de éxito lo evidencia la reciente tapa de la Revista Caras.

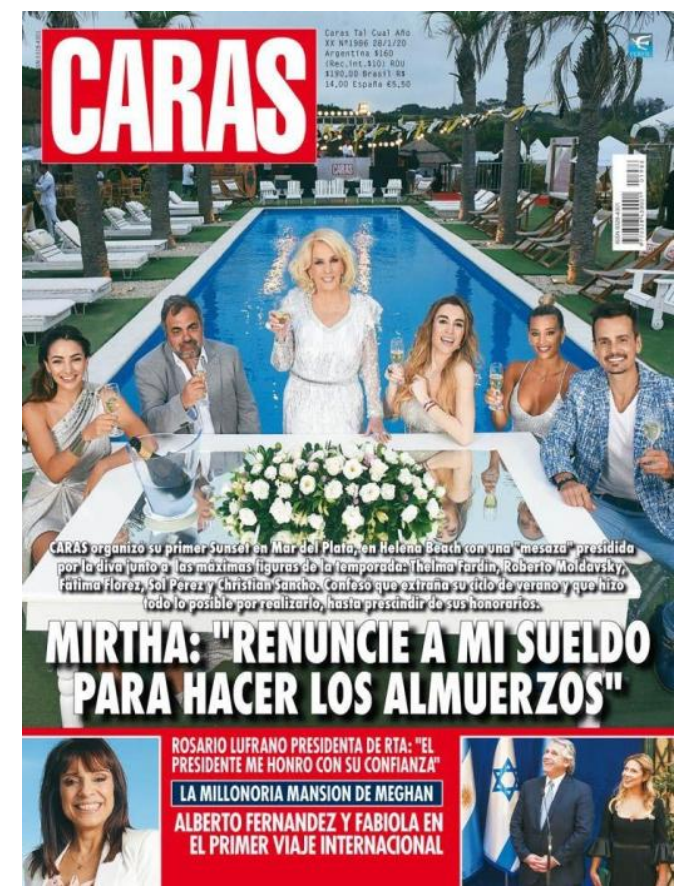

Figura 3. 28 de enero del 2020. Tapa de Revista Caras. (Fuente: Recuperado de: https://caras.perfil.com/noticias/tapas/mirtha-legrand-renuncie-a-mi-sueldo-para-hacer-

Question, Vol. 1, N. ${ }^{\circ}$ 65, abril 2020. ISSN 1669-6581

Instituto de Investigaciones en Comunicación | Facultad de Periodismo y Comunicación Social | Universidad Nacional de La Plata La Plata | Buenos Aires | Argentina 
losalmuerzos.phtml)

Más que pertinente resulta, pues, el enfoque de Sarlo en su artículo sobre Mirtha Legrand en la Revista Orsai. Al inicio de su ensayo Sarlo recuerda una declaración de la diva: "Necesito éxito". Solo en función del éxito y la vigencia se comprende la decisión de trabajar gratis para un gran canal de televisión (Sarlo, 2019).

Resiste al paso del tiempo y su éxito es perdurable gracias a una receta que es siempre, casi exactamente, la misma, independientemente de las metamorfosis acontecidas en el mundo comunicacional. El tiempo físico transcurre y ella no intenta disimularlo. Frente a los cambios se mantiene activa y actualizada. Se aggiorna a la comprensión de la arena política en la que le toca transitar y de cuál es el lugar que debe ocupar para ejercer su papel pedagógico en tanto figura sostén del statu quo. Su invitación a "compartir la mesa" es una invitación a reforzar, desde el sentido común, el mantenimiento de esa ideología conservadora que identificara Sarlo (2019). Resulta sugerente que, ante la ola de transformaciones ocurridas en los últimos 25 años, continúe vigente el diagnóstico que certeramente ofrecía Tabachnik: «los medios no distorsionan, ni simulan, ni "banalizan" lo político: lo producen -en su dimensión pública- en lo que es y puede ser aquí y ahora» (1992, p. 31). En un sentido semejante, en aquel mismo encuentro destinado a reflexionar sobre política y medios de comunicación Quevedo (1997) proponía pensar en «el papel productivo de la Televisión en lo que se refiere a formación de la agenda pública, la construcción de escenarios sociales y políticos, la instalación de ciertos debates y la legitimación y deslegitimación de temas y personas».

Un aspecto adicional que merece ser mencionado en este recorrido vinculado a la cuestión de la cultura política massmediática se refiere a la novedad que, en los últimos años, tuvo lugar en el seno de los programas tradicionalmente conocidos como magazines. En su formato original, que perduró por décadas, los temas propios del género discurrían por la moda, la cocina, el espectáculo, el humor o los chimentos sobre la vida privada de algún personaje famoso. Pero la política constituía un tema ausente. Una primera evaluación podría permitirnos sugerir que fue la confrontación entre medios y gobierno durante el kirchnersimo el hecho que condujo a la politización de estos formatos. De manera tal que los medios no dejaron flanco de la grilla televisiva sin cubrir para garantizar el éxito de su construcción discursiva respecto de la idea de grieta. Sobre esta construcción se organizó (gran) parte de su línea editorial a partir del 2015. Los medios «rotulan» lo político y lo pueden hacer porque controlan en simultáneo varias dimensiones centrales del poder: el régimen de visibilidad, la administración de la palabra y la interlocución con los protagonistas del poder. En efecto, en su análisis, Tabachnik caracterizaba a la Anfitriona como una «figura de pura visibilidad, administradora de la palabra 
ajena e interlocutora autorizada del Poder» (1992, p. 32). El artículo publicado por Sarlo (2019), mencionado anteriormente profundiza sobre la figura de la conductora televisiva a partir de aproximaciones que nos permiten corroborar, una vez más, que se trata de un producto televisivo que, independientemente de las transformaciones que atraviesan los medios, continúa constituyendo una pieza de interés para el análisis de la dimensión cultural de nuestra vida política.

\section{Conclusiones}

En esta etapa de tránsito de la democracia hacia la mediocracia, aparece como un hecho inevitable que los políticos necesiten de los medios y del aire que puedan concederle quienes en ellos gobiernan. No solo Mauricio Macri ha participado de la escena de la comensalidad en vivo y en directo con la legendaria conductora. Tal vez sea difícil encontrar algún miembro de la clase política que se haya negado a participar de un almuerzo o de alguna cena en su mesa. De hecho, Sarlo (2019) recuerda en detalle la participación de Raúl Alfonsín en los años ochenta. Y también podemos recordar aquí el almuerzo que compartieron Néstor Kirchner y Cristina Fernández el 15 de mayo del año 2003. De cara al ballotage, Kirchner había decidido cerrar su campaña almorzando con la conductora. Aunque ese día se hizo pública la noticia de la cancelación de los comicios correspondientes a la segunda vuelta electoral, igualmente acude al planificado almuerzo con la Anfitriona junto a su esposa, por entonces senadora nacional. Nada hizo declinar, a quienes luego gobernarían el país durante más de una década, de la posibilidad de aparecer en esta escena privilegiada del espacio público mediático. ${ }^{13}$ Se trata, por caso, de no olvidar que la primera aparición pública del matrimonio KirchnerFernández, una vez conocida la noticia de que el país sería gobernado por la fórmula KirchnerScioli, tuvo lugar precisamente, en la mesa de Mirtha Legrand, quien poco tiempo después se convertiría en una de sus más férreas críticas.

El sucinto recorrido hasta aquí realizado nos permite aproximarnos a una primera interpretación sobre el modo en que los medios, haciendo foco en la construcción de un escenario de controversia y escisión de la sociedad, enmarcaron la vida política en base a una discursividad que apuntaba a establecer ciertos parámetros de sentido en el contexto de un año electoral. Los dos casos mediáticos aquí revisados intentan contribuir a la comprensión de los modos en que se desarrolla en la actualidad la cultura política massmediática. Es decir, las formas en que

${ }^{13}$ Imágenes del programa disponibles en: https://www.youtube.com/watch?v=67gXZfyGLec 
se abonan espacios mentales para que estos se conviertan en territorios fértiles para la formación de opinión. En una clase de territorio en la cual anide con facilidad la trama de la discursividad política que orienta el voto de amplios sectores de la población. Las nuevas caracterizaciones sobre la democracia, hemos visto, apuntan a explicar los cambios operados en la representación y abren un panorama general para analizar las transformaciones que, correlativamente, también se han producido en el ámbito más amplio de la cultura política. Como intentamos mostrar aquí, desde hace algunos años la grieta es una palabra puesta a disposición de polarizar al electorado entre sectores kirchneristas y antikirchneristas. Su utilización, en términos políticos, fue y parece seguir siendo útil a ciertos sectores de poder, especialmente en épocas de campañas presidenciales. Por ello mismo y para sintetizar la función política de la palabra grieta, haremos caso de una extensa cita en la que, al reflexionar sobre su uso y consecuencias, Horacio González sugiere que «no la empleemos nosotros mismos, porque ya viene envuelta en celofán venenoso, con ponzoña de politólogo oficial (...). Por eso cada vez que la usamos descriptivamente, nos hundimos conceptualmente. (...) La verdadera cuestión es salir de la malla del político profesional en la que estamos envueltos, que es casi la misma con la que escuchamos hablar en los grandes medios de comunicación» (2018). Lo que González afirmaba en pleno auge del término grieta, cuando aún se suponía factible una renovación de la gestión macrista al calor de los favorables resultados en las elecciones legislativas de 2017 , se encuentra en la línea del análisis pos electoral que publica la revista Anfibia. En un artículo del 3 de febrero se sugiere, desde una clara perspectiva austiniana, que: Las palabras hacen cosas. Por tanto, describir un escenario de polarización de la opinión ciudadana haciendo permanente énfasis en la brecha que separa a una opinión de otra, o lo que es igual: remarcando las diferencias como único y exclusivo dato para describir el estado de cosas vigente, contribuye a un determinado modo -en absoluto ingenuo- de fijar agenda sobre la realidad por el que han optado los medios en años recientes (Villanueva, Diego y Aguerre, Tomás, 2020). Divide et impera: la máxima bien conocida por los antiguos romanos cobra hoy inusitada actualidad. Divide y reinarás, de eso se trata en esencia la efectividad de la que es portadora la palabra grieta. En síntesis, la labor de los medios estuvo y continúa estando orientada por el clásico lema romano. Y contra eso, entendemos, nos alertaba González.

De cara al año electoral en curso los medios profundizaron su eje discursivo alrededor de la noción de grieta. Desde los principales programas de los diferentes canales de aire se trazó un escenario de abierta confrontación entre posiciones aparentemente irreconciliables. Como ya sugerimos, resulta claro que el clivaje kirchnerismo/antikirchnerismo vino a reponer, en una nueva versión, el dilema peronismo/antiperonismo que signara la historia argentina a partir de 
la segunda mitad del siglo XX. Lo distintivo, en la versión actual radica en el papel central que los medios y en su seno una parte importante del periodismo, asumieron en la construcción de un periodismo de trinchera (Grimson, 2019) cuyo accionar fue definitivamente útil al propósito de profundizar la división entre sectores del electorado con preferencias contrapuestas. Lo paradójico, en este contexto, es que luego de haber trabajado sistemáticamente para generar una coyuntura signada por una división social irreconciliable, fueron los mismos medios quienes aludieron a la necesidad de generar consensos. Este doble estándar del discurso mediático, poco contribuyó a generar las condiciones de posibilidad para arribar a dichos consensos o acuerdos sobre la base de un proceso de deliberación efectivamente abierto y plural. Así, mientras que desde los medios y desde ciertos sectores de poder se intentó polarizar a la ciudadanía, el trazado de acuerdos para el cierre de listas y fórmulas electorales que ha llevado adelante la clase política, reunió a candidatos que parecían estar parados en lados opuestos de la tan remanida grieta.

\section{Referencias bibliográficas}

Castells, M (1995). La Mediocracia. Diario El País, España, Martes, 24 de enero de 1995. Disponible en https://elpais.com/diario/1995/01/24/opinion/790902010 850215.html Champagne, Patrick (1998). La doble dependencia. En Pilles Gauthier; André Gosselin y Jean Mouchon (comps.) Comunicación y Política. Barcelona: Gedisa, pp. 237-255.

Dahl, Robert (1999). La poliarquía. Madrid: Tecnos.

Exeni, JL (2000). Tras las huellas de la democracia mediática. Comunicación para/desde la Política. Disponible en http://www.clacso.org.ar/biblioteca.

González, H (2010). La grieta esencial. Publicada en Página 12, Opinión, 28/11/2010.

Disponible en: https://www.pagina12.com.ar/diario/elpais/1-157686-2010-11-28.html. Entrada: $12 / 07 / 2019$

González, H (2013). Las grietas lógicas. Publicado en Agencia Paco Urondo, 7/01/2013. Disponible en http://www.agenciapacourondo.com.ar/cultura/las-grietas-logicasporhoraciogonzalez. Entrada 12/07/2019.

González, H (2018). Cuando escucho la palabra grieta. Publicado en La Tecla Ñ, 7/03/2018 https://lateclaenerevista.com/cuando-escucho-la-palabra-grieta-horacio-gonzalez/ Entrada 10/07/2019.

Grimson, A (2019) ¿Qué es el peronismo? De Perón a los Kirchner, el movimiento que no deja de conmover la política argentina. Buenos Aires: Siglo XXI. 
Manin, B (1993). Metamorfosis de la representación, en Mario dos Santos (coord.) ¿Qué es la representación? Caracas: Editorial Nueva Sociedad.

Fuentes de prensa

No quiero volver a la cárcel, pero no le temo (2 de mayo de 2019). La Nación. Recuperado de https://www.lanacion.com.ar/el-mundo/leopoldo-lopez-no-quiero-volver-carcel-peronid2243766

Jorge Lanata empieza la temporada final de Periodismo Para Todos: "En la Argentina no hay una grieta penal" (24 de mayo de 2019). La Nación. Recuperado de https://www.lanacion.com.ar/espectaculos/jorge-lanata-nid2251266

Lanata: "Estoy en contra del periodismo militante" (13 de octubre de 2011). La Nación.

Recuperado de https://www.lanacion.com.ar/politica/lanata-estoy-en-contradelperiodismo-militante-nid1414256

Jorge Lanata, polémico: "El periodismo militante es propaganda" (15 de noviembre de 2017). Rosario Nuestro. Recuperado de: https://rosarionuestro.com/jorge-lanata-polemico-elperiodismo-militantees-propaganda/

Pittella, F. (31 de mayo de 2017). Lanata, el periodista que inventó "la grieta" en 1989. Infobae. Recuperado de: https://www.infobae.com/cultura/2017/05/31/lanata-el-periodista-queinvento-lagrieta-en-1989/

Jorge Lanata: "El periodismo militante no es periodismo, es propaganda" (14 de noviembre de 2017). TN. Recuperado de:https://tn.com.ar/show/basicas/konex-2017jorge-lanata-elperiodismo-militanteno-esperiodismo-es-propaganda_834519

Carbajal, M. (22 de mayo de 2015). Algo habrán hecho. Página 12. Recuperado de: https://www.pagina12.com.ar/diario/sociedad/3-273256-2015-05-22.html

La controvertida pregunta de Mirtha que debió contestar Roberto Piazza (13 de julio de 2010). La Nación. Recuperado de: https://www.lanacion.com.ar/sociedad/la-controvertidapregunta-de-mirthaque-debio-contestarroberto-piazza-nid1284275 